mSASSS and the RASSS performed the best in terms of capturing the signal (i.e. positive change) despite the noise (i.e. negative change), which is taken into account in the net change calculation.

The proportion of variance explained by the patient for the radiographic scores was highest for the mSASSS and RASSS, both for status and progression scores (e.g. $70 \%$ for mSASSS 69\% for RASSS 2 year progression). However, the proportion of patient variance in the thoracic segment of the RASSS was unsatisfactory (36\% for 2 year progression, compared to $54 \%$ lumbar segment and $73 \%$ cervical segment).

In what concerns feasibility, all scores seemed feasible, but the thoracic segment was missing in up to $7 \%$ of the cases, thus not allowing computation of BASRI modifications to include that segment.

Abstract THU0272 - Table 1. Two- and 5-year change, above the smallest detectable change, across the different radiographic scores

\begin{tabular}{|c|c|c|c|c|c|c|c|c|c|c|}
\hline & \multicolumn{5}{|c|}{ 2-year Change > SDC } & \multicolumn{5}{|c|}{ 5-year Change > SDC } \\
\hline & $\mathrm{N}$ & SDC & \begin{tabular}{|l} 
Positive \\
change \\
N (\%)
\end{tabular} & $\begin{array}{l}\text { Negative } \\
\text { change } \\
\mathrm{N}(\%)\end{array}$ & $\begin{array}{c}\text { Net } \\
\text { change } \\
\text { N (\%) }\end{array}$ & $\mathrm{N}$ & SDC & $\begin{array}{l}\text { Positive } \\
\text { change } \\
\mathrm{N}(\%)\end{array}$ & $\begin{array}{l}\text { Negative } \\
\text { change } \\
\mathrm{N}(\%)\end{array}$ & $\begin{array}{c}\text { Net } \\
\text { change } \\
\mathrm{N}(\%)\end{array}$ \\
\hline mSASSS (0.72) & 488 & 0.9 & $29(6)$ & $6(1)$ & $23(5)$ & 372 & 1.1 & $41(11)$ & $3(1)$ & $38(10)$ \\
\hline 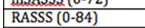 & 484 & $\frac{0.9}{1.0}$ & $\frac{29(0)}{26(5)}$ & $\frac{0(1)}{2(0.4)}$ & $\frac{25(5)}{24(5)}$ & $\frac{376}{370}$ & $\frac{1.1}{1.2}$ & $\frac{41(11)}{54(15)}$ & $\frac{3(1)}{1(0.3)}$ & $\frac{30(10)}{53(14)}$ \\
\hline SASSS $(0-72)$ & 499 & 0.8 & $13(3)$ & $0(0)$ & $13(3)$ & 389 & 1.2 & $36(9)$ & $0(0)$ & $36(9)$ \\
\hline$\frac{\text { SASSSI (0-/L) }}{\text { BASRI spine (0-12) }}$ & 489 & 0.8 & $\frac{13(3)}{40(8)}$ & $\frac{0(0)}{22(5)}$ & $\frac{13(3)}{18(4)}$ & $\frac{389}{371}$ & $\frac{1.2}{0.7}$ & $\frac{36(9)}{39(1)}$ & $\frac{0(0)}{2(0.5)}$ & $\frac{36(9)}{37(10)}$ \\
\hline $\begin{array}{l}\text { BASRI spine with } \\
\text { thoracic }(0-16)\end{array}$ & 360 & 0.6 & $35(10)$ & $17(5)$ & $18(5)$ & 267 & 0.9 & $31(12)$ & $2(1)$ & $29(11)$ \\
\hline $\begin{array}{l}\text { tharacic }(0.16) \\
\text { BASRI total (0-16) }\end{array}$ & 480 & 0.6 & $41(9)$ & $22(6)$ & $19(4)$ & 368 & 0.8 & $41(11)$ & $2(0.5)$ & $39(11)$ \\
\hline BASRI total with & 358 & 0.7 & $19(4)$ & $4(1)$ & $15(3)$ & 266 & 0.9 & $32(12)$ & $2(1)$ & $30(11)$ \\
\hline
\end{tabular}

Conclusions: The existing scoring methods to assess spinal radiographic damage performed well in early phases of axSpA. The mSASSS and RASSS captured most change. There was no clear gain in additionally scoring the thoracic spine for the RASSS while an increased noise was introduced. The mSASSS remains the most sensitive and valid scoring method in axSpA, including early phases of the disease.

Disclosure of Interest: None declared

DOI: 10.1136/annrheumdis-2018-eular.2882

\section{THU0273 PREVALENCE OF VERTEBRAL FRACTURES IN ANKYLOSING SPONDYLITIS: A META-ANALYSIS}

J. Sahuguet ${ }^{1}$, J. Mancini ${ }^{2}$, P. Lafforgue ${ }^{3},{ }^{3}$ T. Pham. ${ }^{1}$ Aphm, Hopital Sainte Marguerite; ${ }^{2}$ Aix Marseille Univ, Inserm, Ird, Umr912 Sesstim; ${ }^{3}$ Aix Marseille Univ, Aphm, Hopital Sainte Marguerite, Marseille, France

Background: Osteoporosis is a well-recognised feature of ankylosing spondylitis (AS). Patients with AS have an increased risk of vertebral fractures (VF) but prevalence of VF is variable across studies from $4 \%$ to $42 \%$. The diagnosis of VF is still problematic because frequently asymptomatic and sometimes difficult to differentiate from vertebral deformities which are not fractures.

Objectives: The aim of our study was to determine the prevalence of VF in AS and the risk factors associated.

Methods: Two independent investigators conducted a search in Medline and Cochrane databases, including cohorts, cross-sectional, and case-control studies that had assessed the prevalence of VF in patients with AS fulfilling the modified New York criteria. We collected data about study design, demographics, disease activity and severity (HLA B27 antigen status, BASDAI, BASFI, ASDAS, mSASSS, CRP, ESR, treatment history), bone mineral density, method of VF assessment (method of $X$-rays reading, number of readers) and characteristics of VF (number, prevalence, grade).

Results: Among 434 screened studies, 17 were eligible for meta-analysis. The pooled VF prevalence in patients with AS was $19 \%\left(95 \% \mathrm{Cl} 14 \%>24 \%, \mathrm{I}^{2} 90.5 \%\right)$ (figure 1). The CRP $(p<0.001)$ and mSASSS $(p=0.046)$ scores were associated with a higher risk of VF. When focusing only on moderate to severe VF, HLA B27 antigen $(p=0.046)$, lumbar spine osteoporosis $(p=0.018)$ and osteopenia $(p=0.024)$, hip BMD $(p=0.024)$, CRP $(p=0.004)$, ESR $(p<0.001)$, and Genant method $(p=0.009)$ were associated with higher risk of VF.

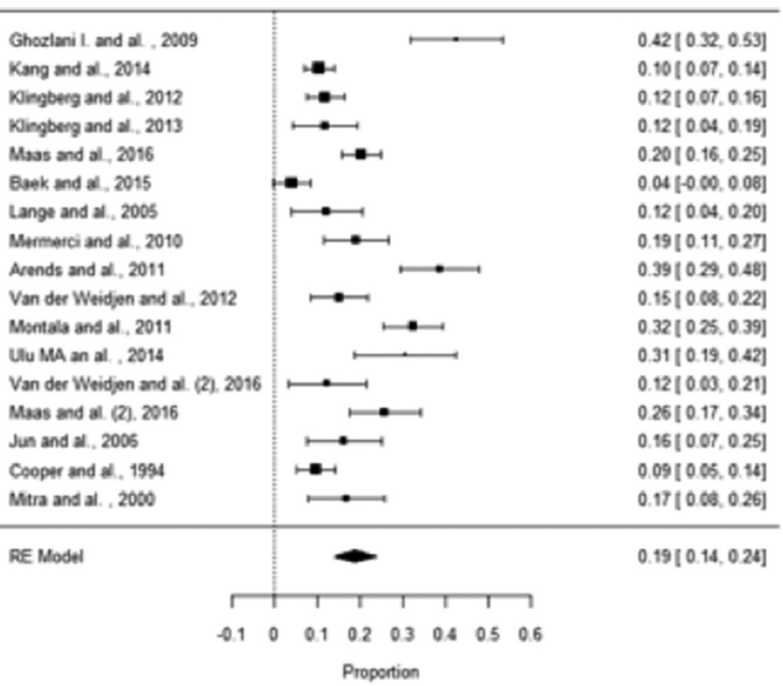

Conclusions: Despite a large heterogeneity among studies, the prevalence of VF in AS patients is high. CRP and mSASSS scores were associated with the prevalence of all VF. Classical VF risk factors, such as osteoporosis, were associated only with moderate and severe VF.

Disclosure of Interest: None declared

DOI: 10.1136/annrheumdis-2018-eular.5191

\section{THU0274 ASSESSMENT OF RADIOGRAPHIC SACROILIITIS ON ANTERO-POSTERIOR LUMBAR RADIOGRAPHS AS COMPARED TO CONVENTIONAL PELVIC RADIOGRAPHS IN PATIENTS WITH AXIAL SPONDYLOARTHRITIS}

${ }^{1}$ V. Rios Rodriguez, M. Llop ${ }^{1}$, M. Protopopov ${ }^{1}$, J. Sieper ${ }^{1}$, H. Haibel ${ }^{1}$, M. Rudwaleit ${ }^{2}$, D. Poddubnyy ${ }^{1,3}$. ${ }^{1}$ Rheumatology, Charité Universitätsmedizin, Berlin; ${ }^{2}$ Internal Medicine and Rheumatology, Klinikum Bielefeld Rosenhöhe, Bielefeld; ${ }^{3}$ German Rheumatism Research Centre, Berlin, Germany

Background: EULAR guidelines consider conventional radiography of sacroiliac joints (SIJs) as the first recommended imaging method in case of suspected axial spondyloarthritis (axSpA). ${ }^{1}$ However, it is not clear whether sacroiliac joints can be reliably assessed on anteroposterior (AP) lumbar radiographs, which are often performed as a part of the diagnostic work-up in patients presented with back pain.

Objectives: To investigate reliability and validity of radiographic sacroiliitis assessment on AP lumbar radiographs as compared to conventional pelvic $\mathrm{X}$ rays in patients with axSpA.

Methods: Patients from the GErman SPondyloarthritis Inception Cohort (GESPIC) were selected based on the availability of sets of pelvic and AP lumbar radiographs with visible SIJs at baseline and after 2 years of follow-up. Two trained readers ( $M L$ and VR) scored the images independently and in a random order according to the radiographic system of the modified New York (mNY) criteria (grade 0 to 4 ). The sacroiliitis sum score $(0-8)$ was calculated as a sum of the mean grades of 2 readers for the right and left SIJ. We assessed intra- and interreader reliability using intraclass correlation coefficients (ICC) of the sacroiliitis sum scores. Patients were classified as having radiographic axSpA ( $r$-axSpA) when both readers agreed on the presence of definite radiographic sacroiliitis according to the $\mathrm{mNY}$ criteria, and non-radiographic axSpA (nr-axSpA) otherwise. Results: A total of 226 sets radiographs were scored from the 113 patients included in the present study. Intra-observer agreement was good to excellent for 
the sacroiliitis sum score of pelvic vs. AP lumbar radiographs. Inter-observer agreement for pelvic and AP lumbar radiographs was also good to excellent: ICC at baseline: 0.81 and 0.73 , respectively, at year $2: 0.76$ and 0.79 , respectively. A total of $62(54.9 \%)$ and $55(48.7 \%)$ patients were classified as $r-a x S p A$ at baseline based on evaluation of pelvic and AP lumbar radiographs, respectively. The absolute agreement on the classification was $84.9 \%$ (figure 1 ). A total of 17 patients (12 (10.6\%) with nr-axSpA and $5(4.4 \%)$ with r-axSpA) were classified differently based on assessment of AP lumbar as compared to conventional pelvic radiographs (figure 1 ).

After 2 years of follow-up, progression from nr- to r-axSpA occurred in 7 patients $(6.2 \%)$ and 8 patients $(7.1 \%)$ classified as $\mathrm{nr}-\mathrm{axSpA}$ at baseline based on pelvic or AP lumbar radiographs assessment, respectively. Regression from $\mathrm{r}$ - to $\mathrm{nr}$ axSpA occurred in 4 patients (3.5\%) and 3 patients $(2.7 \%)$ on pelvic or AP lumbar radiographs, respectively, giving a respective net progression rates of $2.7 \%$ and $4.4 \%$.

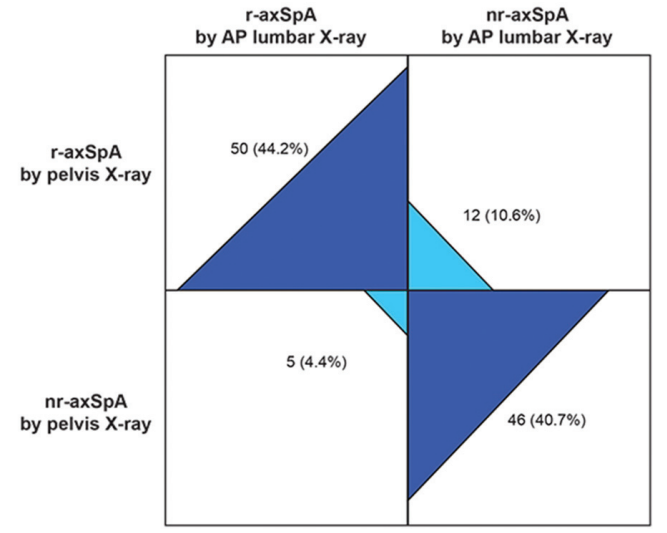

Abstract THU0274 - Figure 1. Classification as non-radiographic or radiographic axial spondyloarthritis based on sacroilitis assessment on conventional pelvic and anteroposterior lumbar radiographs.

Conclusions: Radiographic sacroiliitis can be assessed on AP lumbar radiographs with a similar reliability as on conventional pelvic radiographs.

\section{REFERENCE:}

[1] Mandl P, et al. Ann Rheum Dis 2015;74(7):1327-39.

Acknowledgements: GESPIC was financially supported by the German Federal Ministry of Education and Research (BMBF) 2000-2007. 2005-2009 complementary financial support was obtained also from Abbott/Abbvie, Amgen, Centocor, Schering-Plough, and Wyeth. Since 2010 GESPIC is supported by Abbvie.

The work of Maria Llop was supported by EULAR Scientific Bursary and by FER Institution (Fundación Española de Reumatología).

Disclosure of Interest: V. Rios Rodriguez Consultant for: Abbvie, Novartis, M. Llop: None declared, M. Protopopov: None declared, J. Sieper Grant/research support from: Abbvie, MSD, Pfizer, Consultant for: Abbvie, MSD, Pfizer, UCB, H. Haibel: None declared, M. Rudwaleit Consultant for: Abbvie, MSD, Pfizer, UCB, D. Poddubnyy Grant/research support from: Abbvie, MSD, Novartis, Consultant for: Abbvie, BMS, MSD, Novartis, Pfizer, UCB, Speakers bureau: Abbvie, BMS, Janssen, MSD, Novartis, Pfizer, Roche, UCB

DOI: 10.1136/annrheumdis-2018-eular.5654

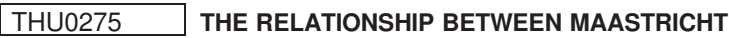 ANKYLOSING SPONDYLITIS ENTHESITIS SCORE AND THE SPONDYLOARTHRITIS RESEARCH CONSORTIUM OF CANADA ENTHESITIS INDEX IN ANKYLOSING SPONDYLITIS: FRIENDS OR ENEMIES?}

${ }^{1}$ W. Hamdi, M. Sellami ${ }^{1}$, H. Riahi ${ }^{2}$, K. Maatallah ${ }^{1}$, D. Kaffel ${ }^{1}$, M. Chelli-Bouaziz ${ }^{2}$, M. F. Ladeb ${ }^{2}$, M.M. Kchir ${ }^{1} .{ }^{1}$ Rheumathology; ${ }^{2}$ Radiology, Kassab Orthopedics Institute, Manouba, Tunisia

Background: The enthesitis screening is critical for the diagnosis and for monitoring the disease activity in axial spondyloarthritis(AS). Several indices have been developed for the clinical evaluation of enthesitis, including the Maastricht Ankylosing Spondylitis Enthesitis Score (MASES) in 2003 and the Spondyloarthritis Research Consortium of Canada (SPARCC) in 2008. Each of them has advantages and limitations, but could they be complementary?
Objectives: The objective of our study was to compare the abilities of MASES and SPARCC in detecting enthesitis and to look for possible correlations between these two scores.

Methods: We designed this prospective study in 60 patients meeting modified New York criteria for AS and seen at the rheumatology department. All patients underwent a clinical evaluation, in which scores of MASES (range 0-13) SPARCC (range 0-16) and visual analogue scale (VAS) for entheseal pain were recorded. Ultrasound scans were taken for five entheses sites on both sides in lower limbs (proximal and distal insertions of the patellar tendon, patellar insertion of the quadriceps tendon, and calcaneal insertions of the Achilles tendon and superficial plantar fascia).

Results: Sixty AS patients were enrolled (48 men and 12 women) with a mean age of 36 years $^{20-74}$ and mean disease duration of 8.8 years [0.5-25]. Biological inflammation was detected in 51 patients with mean erythrocyte sedimentation rate (ESR) of $33^{2-98}$ and mean $C$ reactive protein of $16.9 \mathrm{mg} / \mathrm{L}[0-240]$. Physical examination found $77 / 600$ painful entheses sites(12.8\%), of which quadriceps and calcaneum entheses were the most painful in $16 \%$ and $15.8 \%$ cases respectively. The mean MASES was 3.4 [0-13] and the mean SPARCC was 2.98 [0-16]. A null MASES and SPARCC scores were recorded in 18 (30\%) and $23(38 \%)$ patients respectively. US imaging of the entheses showed peritendinous oedema and bursitis mainly at distal insertions of the patellar tendon in $51 \%$ and $55 \%$ respectively. Erosions were more likely detected at Achilles tendon site (95.8\%). MASES and SPARCC scores were both significantly correlated with VAS for entheseal pain $(r=0.52 ; r=0.46 ; p<0.0001$ respectively), with the BASDAI $(r=0.39$ $r=0.40 ; p<0.0001$ respectively), with BASFI $(r=0.45 ; r=039 ; p<0.0001)$, with VAS for global pain $(r=0.55 ; r=0.51 ; p<0.0001$ respectively) and with ESR ( $r=0.23$ $\mathrm{p}=0.012$ for both). The sonographic score for acute enthesitis correlated only with the MASES, however overall sonographic score correlated only with the SPARCC (table 1). The MASES and SPARCC scores were positively correlated $(r=0.768$; $\mathrm{p}<0.0001)$.

Abstract THU0275 - Table 1. Correlations among clinical and sonographic scores.

\begin{tabular}{lcccc}
\hline $\begin{array}{l}\text { Enthesitis } \\
\text { indices }\end{array}$ & $\begin{array}{c}\text { Sonographic score for } \\
\text { acute enthesitis }\end{array}$ & $\begin{array}{c}\text { Overall } \\
\text { sonographic } \\
\text { score }\end{array}$ & $\begin{array}{c}\text { Sonographic score for } \\
\text { chronic enthesitis }\end{array}$ & $\begin{array}{c}\text { Doppler } \\
\text { score }\end{array}$ \\
\hline MASES & $\mathrm{r}=0.24$ & $\mathrm{r}=0.114$ & $\mathrm{r}=0.14$ & $\mathrm{r}=0.1$ \\
& $\mathrm{p}=0.008$ & $\mathrm{p}=0.2$ & $\mathrm{p}=0.12$ & $\mathrm{p}=0.27$ \\
SPARCC & $\mathrm{r}=0.15$ & $\mathrm{r}=0.198$ & $\mathrm{r}=0.17$ & $\mathrm{r}=0.12$ \\
& $\mathrm{p}=0.09$ & $\mathrm{p}=0.030$ & $\mathrm{p}=0.05$ & $\mathrm{p}=0.18$ \\
\hline
\end{tabular}

Conclusions: Good correlations were found between the 2 enthesitis indices in AS with special sonographic featuresfor each, attesting their complementary relationship.

Disclosure of Interest: None declared

DOI: 10.1136/annrheumdis-2018-eular.5566

\section{THU0276 MRI LESION DEFINITIONS IN AXIAL SPONDYLOARTHRITIS: A CONSENSUS REAPPRAISAL FROM THE ASSESSMENTS IN SPONDYLOARTHRITIS INTERNATIONAL SOCIETY (ASAS)}

${ }^{1}$ W.P. Maksymowych, R.G. Lambert ${ }^{2}$, M. Østergaard ${ }^{3}$, M. de Hooge ${ }^{4}$, S. J. Pedersen ${ }^{5}$, A.N. Bennett ${ }^{6}$, R. Burgos-Vargas ${ }^{7}$, I. Eshed $^{8}$, R. Landewé ${ }^{9}$, P. Machado ${ }^{10}$, H. Marzo-Ortega ${ }^{11}$, D. Poddubnyy ${ }^{12}$, M. Rudwaleit ${ }^{13}$, J. Sieper ${ }^{12}$, D. van der Heijde ${ }^{14}$, I. Van der Horst-Bruinsma ${ }^{15}$, U. Weber $^{16}$, X. Baraliakos ${ }^{17}$. ${ }^{1}$ Medicine; ${ }^{2}$ Radiology, University of Alberta, Edmonton, Canada; ${ }^{3}$ Rheumatology, Copenhagen Center for Arthritis Research, Copenhagen, Denmark;

${ }^{4}$ Rheumatology, Ghent University and Ghent University Hospital, Ghent, Belgium; ${ }^{5}$ Rheumatology, Gentofte Hospital, Copenhagen, Denmark; ${ }^{6}$ Rheumatology, Imperial College, London, UK; ${ }^{7}$ Rheumatology, Universidad Nacional Autonoma de Mexico, Mexico City, Mexico; ${ }^{8}$ Radiology, Sheba Medical Center, Tel Aviv, Israel; ${ }^{9}$ Rheumatology, Academic Medical Center, Amsterdam, Netherlands;

${ }^{10}$ Rheumatology, University College London, London; ${ }^{11}$ Rheumatology, University of Leeds, Leeds, UK; ${ }^{12}$ Rheumatology, Charité Universitätsmedizin Berlin;

${ }^{13}$ Rheumatology, Klinikum Bielefeld Rosenhöhe, Berlin, Germany;

${ }^{14}$ Rheumatology, Leiden University Medical Center, Leiden; ${ }^{15}$ Rheumatology, VU University Medical Center, Amsterdam, Netherlands; ${ }^{16}$ Rheumatology, King Christian 10th Hospital for Rheumatic Diseases, Graasten, Denmark;

${ }^{17}$ Rheumatology, Rheumazentrum Ruhrgebiet, Herne, Germany

Background: There has been substantial progress in the characterisation of MR lesions in the sacroiliac joints (SIJ) and spine in axial spondyloarthritis (axSpA) since the last consensus-based descriptive reports from $A S A S^{1,2}$. There is as yet a lack of international consensus on standardised definitions of all the lesions reported to date. Consequently, the ASAS MRI group was convened to generate a consensus update. 